УДК 539.214

\title{
Mathematical Modeling of Plastic Deformation in FCC Metals
}

\author{
Svetlana N. Kolupaeva* \\ Tomsk State University of Architecture and Building \\ Solyanaya, 2, Tomsk, 634003 \\ Russia \\ Valeriy I.Ryumkin ${ }^{\dagger}$ \\ Alexander E. Petelin $\ddagger$ \\ National Research Tomsk State University \\ Lenin Ave., 36, Tomsk, 634050 \\ Russia
}

Received 04.07.2017, received in revised form 07.10.2017, accepted 18.01.2018

A study was made of the number of dislocations change in the crystallographic shift zone for fcc metals: lead, aluminum and copper, depending on the magnitude of the acting stress and other factors affecting the formation of the shear zone, using a mathematical model that takes into account the influence of the basic resistance mechanisms to the propagation of a dislocation loop.

Keywords: plastic deformation, dislocation, crystallographic slip, shear zone, fcc materials, mathematical modeling.

DOI: $10.17516 / 1997-1397-2018-11-2-242-248$.

\section{Introduction}

Plastic deformation of metals is of great practical importance, since it leads to an irreversible change in the structure of metals and their properties.

It is realized advantageously crystallographic slip mechanisms representing a displacement of one relative to the other metal layers. The process of plastic deformation can be represented as a set of elementary crystallographic slides confined within the crystal by closed dislocations (dislocation loops) separating the region where the slip passed from the rest of the slip plane.

Such a set of emerging dislocations forms a zone of crystallographic shear [1]. Crystallographic shear zone is decisive structural element of crystallographic slip. The time of the shear zone formation is much less than the duration of the deforming effect.

Crystallographic slip processes develop at various structural and scale levels. It is during the formation of the crystallographic shear zone that basic defects are generated-dislocations and point defects. Thus, plastic deformation is represented by crystallographic shifts localized in certain slip planes. The height of the step of the shear, arising on the surface of the crystal as a result of plastic deformation, can reach tens, hundreds and thousands of lengths of the Burgers vector.

\footnotetext{
*ksn58@yandex.ru

$\dagger$ viruvir53@mail.ru

$\ddagger$ aepetelin@gmail.com

(c) Siberian Federal University. All rights reserved
} 
Investigating the dynamics of the elementary slips formation is a complex task, both for experimental study and for mathematical modeling, since in the propagation of elementary slip, the dislocation limiting it overcomes many obstacles of different nature and different strength [2].

A full-scale study of the zone of crystallographic shear formation under various conditions is impossible without the use of a combination of experimental, analytical methods and methods of computer modeling. Among methods of computer research of the mechanisms and processes of dislocation movement in the field of discrete obstacles in the formation of a zone of crystallographic shear, the methods of simulation modeling are dominant [3-9]. These methods are widely used to study the localization of deformation along with X-ray diffraction analysis and other experimental methods. In this field, significant results were obtained by the representatives of the Tomsk school M. V. Slobodskoy and L. E. Popov [8], [9] using simulation simulation of dislocation motion in the field of discrete obstacles.

The methods of simulation are very effective, but at the same time extremely laborious. Alternative methods are methods of mathematical modeling [10-15].

The use of mathematical models makes it possible to reveal the general (integral) character of the zone of crystallographic shear formation under various conditions, although it does not give particular details of the entire pattern of the dislocation loops passage through a set of random obstacles. The use of these types of models also has its difficulties. Thus, the number of dislocations in the zone of the crystallographic shear can reach tens, hundreds and thousands, and each of the dislocations, as a rule, overcomes tens of thousands of obstacles.

In the work of Mott [10], the first mathematical models of the dislocations dynamics were presented and investigated, which later on were developed in the works of V.D. Natsik and K. A. Chishko [11], N. A. Tyapunina [12], L. E. Popov and S. N. Kolupaeva [13], A. E. Petelin [15], [16] and others.

Metals with a face-centered cubic (fcc) lattice $(\mathrm{Pb}, \mathrm{Al}, \mathrm{Cu}$, etc.) have high plasticity, sliping in them occurs in many directions.

The purpose of this work is to study the changes in the number of dislocations in the shear zone for lead, aluminum and copper, depending on the value of the acting stress and other factors affecting the formation of the crystallographic shear zone.

\section{Mathematical model}

Based on the law of conservation of energy for a closed dislocation loops in the paper of L. E. Popov, S. N. Kolupaeva et al. [13] was obtained a mathematical model of the crystallographic slip dynamics of dislocation loop. This model is a system of ordinary differential equations:

$$
\left\{\begin{array}{r}
\frac{d \varepsilon_{k}^{(i)}}{d r}=\left(\tau b-\frac{p_{j} p_{s} \xi}{8} G b^{2} r \rho-\frac{G b^{2}(i-1)}{2 \pi} \frac{2-\nu}{2(1-\nu)} \frac{1}{D / 2-r}-\frac{\mu_{0}+\varepsilon_{k}^{(i)}}{r}-\tau_{R} b-\right. \\
\left.-B c \sqrt{1-\left(\frac{\varepsilon_{k}^{(i)}}{\varepsilon_{0}}+1\right)^{-2}}\right) c \sqrt{1-\left(\frac{\varepsilon_{k}^{(i)}}{\varepsilon_{0}}+1\right)^{-2}}, \\
\frac{d r}{d t}=c \sqrt{1-\left(\frac{\varepsilon_{k}^{(i)}}{\varepsilon_{0}}+1\right)^{-2}} .
\end{array}\right.
$$

Here $\tau$ is the external stress, $\varepsilon_{k}^{(i)}$ is the kinetic energy per unit length of the moving $i$ th dislocation emitted by the dislocation source, $r$ is the radius of the dislocation loop, $\xi$ is the Smallman 
multiplier, $p_{j}$ is the fraction of threshold-forming dislocations of noncoplanar slip systems, $p_{s}$ is the fraction of threshold-forming dislocations on the outline segments of the dislocation loop, $c$ is the sound velocity in the crystal, $B$ is the coefficient of viscous inhibition, $G$ is the shear modulus, $b$ is the modulus of the Burgers vector, $\nu$ is the Poisson's ratio, $\rho$ is the dislocation density, $D$ is the shear zone diameter, $\mu_{0}$ is the linear tension of the dislocation, $\tau_{R}=\tau_{f}+\tau_{d}$, where $\tau_{f}$ is the stress of the lattice and impurity friction, $\tau_{d}=\alpha G \rho^{1 / 2}$ is the dislocation resistance to the propagation of crystallographic slip, $\alpha$ is the parameter characterizing the intensity of interdislocation interactions. The terms on the right-hand side of the first equation of system (1) represent, respectively, the Pich-Kohler force and the resistance forces due to: the action of inverse stress fields from the side of the dislocation cluster, the linear tension of the moving dislocation, the overcoming of lattice, impurity and dislocation friction, viscous inhibition and point defects generation.

Thus, in the model (1), the Pich-Kohler forces due to the applied action are taken into account, the forces of resistance to the movement of dislocations caused by lattice, impurity and dislocation friction, viscous inhibition, inverse stress fields from accumulation of previously emitted dislocations, and also by linear tension of dislocations and the generation of point defects beyond the thresholds on a dislocation; the dependence of the linear tension force of the dislocation and the intensity of point defects generation beyond the thresholds on dislocations from the orientation of the Burgers vector In relation to the dislocation line.

All parameters of the model (1) have a physical meaning and, as a rule, are the characteristics of the material or the effect on it. This model can be used to study the energy, scale and time characteristics of elementary crystallographic slip and the shear zone as a whole, taking into account the dependence of the linear tension force of the dislocation and the intensity of the generation of point defects.

\section{Research results}

The investigations were carried out on the basis of a mathematical model of crystallographic slip dynamics (1). The values of the basic parameters of the model used according to independent experimental and theoretical studies of various authors. Modeling was carried out for copper, aluminum and lead using the Dislocation Dynamics of Crystallographic Slip (DDCS) software package, developed by S. N. Kolupaeva and A. E. Petelin [14], and designed to implement the mathematical model of the dislocation dynamics of crystallographic slip in fcc metals. To find the solution of the system of ordinary differential equations (1) in the DDCS software complex, the Gear method is used. To build the acceleration points needed for the Gyr method, the explicit Adams method is used. It is assumed that at a time $t=0$, the dislocation source segment has the form of a circle of radius $r_{c}$. The equations are solved under the conditions of the following Cauchy problem: $\varepsilon_{k}^{(i)}(0)=0, r(0)=r_{c}$. The calculations were carried out for room temperature, the dislocation density $10^{12} \mathrm{~m}^{-2}$, the values of the lattice and impurity friction of $1 \mathrm{MPa}$, the critical (minimum) length of the dislocation source, the fraction of threshold-forming dislocations on the outline segments of the dislocation loop equal to $1 / 3$, and for 50 percent of the threshold-forming dislocations of noncoplanar slip systems. In each separate calculation, one of the parameters of the mathematical model (1) changed with the other parameters unchanged. As a result of the study, an increasing nonlinear logarithmic dependence of the number of dislocations in the zone of the crystallographic shear on the magnitude of the acting stress was revealed (Fig. 1).

It is shown that for an equal value of the external acting stress $\tau$, the number of dislocations 


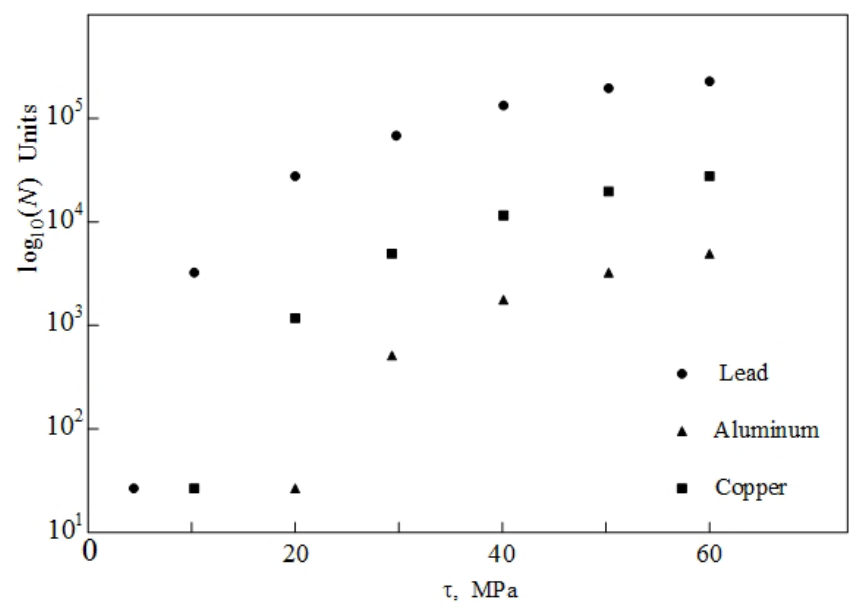

Fig. 1. The number of dislocations in the shear zone at different values of the effective stress

in the crystallographic shear zone in aluminum is an order of magnitude higher than in copper and an order of magnitude lower than in lead. With a value of the lattice and impurity friction $\tau_{f}$ equal to $1 \mathrm{MPa}$, the number of dislocations in the zone of the crystallographic shear in copper, aluminum and lead is approximately 30 dislocations (Fig. 2).

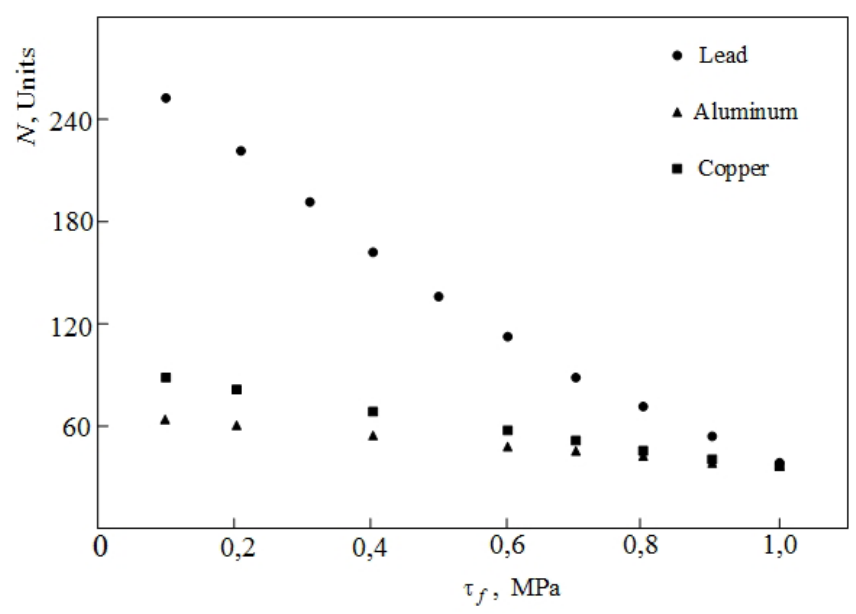

Fig. 2. The number of dislocations in the shear zone at different values of the lattice and impurity friction

With decreasing $\tau_{f}$, a practically linear increase in the number of dislocations is observed for each of the metals studied. When the lattice and impurity friction is reduced by an order of magnitude, the number of dislocations in the shear zone in copper is doubled, in aluminum by almost three times, and in lead by almost eight times.

At a minimum length $d$ of a dislocation source, at which emission of dislocation loops is possible, defined as [1]: $d=(\sqrt{0,14 \xi \rho})^{-1}$, the number of dislocations in the shear zone in copper, aluminum and lead varies insignificantly and is equal to $\approx 30$.

As the length of the dislocation source increases the number of dislocations in the shear zone increases by almost an order of magnitude, reaching a maximum value about 200 dislocations, and 
then decreases (Fig. 3). At the same length of the dislocation source the number of dislocations in the shear zone in copper is on average 10 percent higher than in aluminum and an average of 20 percent less than in lead.

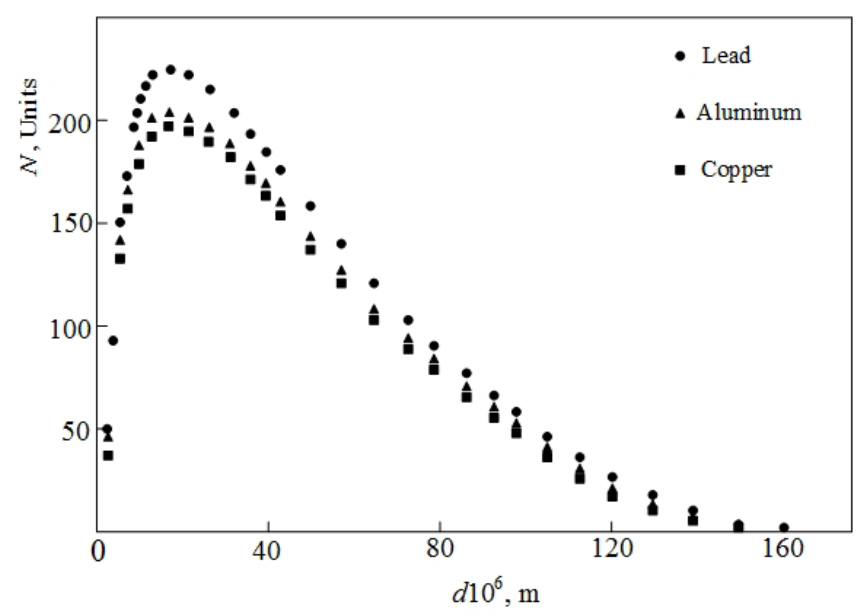

Fig. 3. The number of dislocations in the shear zone at different values of the dislocation source length

\section{Conclusion}

As a result of the study, it was shown that when the density of dislocations decreases from $10^{12}$ to $10^{11} \mathrm{~m}^{-2}$, the number of dislocations in the zone of the crystallographic shear increases by two orders of magnitude (Fig. 4). In copper, aluminum, and lead, the number of dislocations for identical values of dislocation density differs insignificantly.

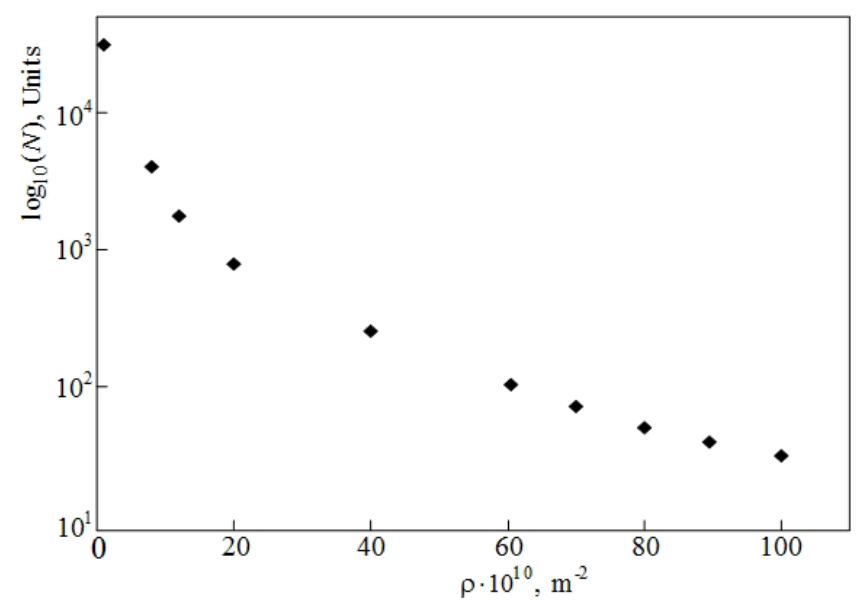

Fig. 4. The number of dislocations in the shear zone at different values of the dislocation density

Thus, as a result of the investigation, a significant dependence of the number of dislocations in the zone of the crystallographic shift on the effective stress and dislocation density is revealed. A complex dependence of the number of dislocations in the zone of the crystallographic shear 
on the dislocation source length, which has a rapidly increasing character at a relatively small dislocation source length and a slowly decreasing character at large lengths of the dislocation source is shown.

\section{References}

[1] L.E.Popov, M.I.Slobodskoi, S.I.Kolupaeva, Simulation of single slip in FCC metals, Russian physics journal, 49(2006), no. 1, 62-73.

[2] J.Hirth, J.Lothe, Theory of Dislocations, New York, McGraw-Hill, 1968.

[3] A.J.E.Foreman, M.J.Makin, Dilocation Movement through Random Arrays of Obstracles, Can. J. Phys., 45(2P2)(1967), 511-517.

[4] A.S.Argon, Thermally activated motion of dislocation, Phil. Mag.: J. Theor. Exper. and Appl. Phys., 25(1972), no. 5, 1053-1072.

[5] J.W.Morris, D.H.Klahn, Thermally activated dislocation glide through a random array of point obstacles: Computer simulation, J. Appl. Phys., 45(1974), no. 5, 2027-2036.

[6] R.Labusch, R.W.Schwars, Movement of dislocations through a random of weak obstacles of finite width, Nuclear Metallurgy, 20(1976), 657-671.

[7] B.M.Loginov, A.A.Predvoditelev, Modeling the motion of dislocations through a forest of flexible and reactive dislocations, Fizika Tverdogo Tela, 23(1981), no. 1, 112-116 (in Russian).

[8] M.I.Slobodskoi, L.E.Popov, Investigation of the sliding phenomena in crystals by methods of simulation, Tomsk, TSUAB, 2004 (in Russian).

[9] M.I.Slobodskoi, L.E.Popov, Features of the Frank-Read source work in a field of randomly located obstacles, Bulliten Ros. Akad. Nauk. Fizika, 62(1998), no. 7, 1339-1344 (in Russian).

[10] N.F.Mott, A theory of work-hardering of metal crystals, Phil. Mag.: J. Theor. Exper. and Appl. Phys., 43(1952), no. 346, 1151-1178.

[11] V.D.Natsik, K.A.Chishko K.A., Dynamics and sound radiation of the Frank-Read dislocation source, Condensed Matter Physics: Collected Works of the Physico-Technical Institute of Low Temperatures of the Academy of Sciences of the Ukrainian SSR, 33(1974), 44-57 (in Russian).

[12] N.A.Tyapunina, E.K.Naimi, G.M.Zinenkova, The effect of ultrasound on crystals with defects, Moscow, Moscow State University, 1999 (in Russian).

[13] L.E.Popov, S.N.Kolupaeva, N.A.Vihor, S.I.Puspesheva, Dislocation dynamics of elementary crystallographic shear, Computational Materials Science, 19(2000), 267-274.

[14] A.E.Petelin, S.N.Kolupaeva, Automation of the crystallographic slip study in FCC metals, Trudy Tomskogo Politeh. Univer., 316(2010), no. 5, 141-146 (in Russian).

[15] A.E.Petelin, S.I.Samokhina, S.N.Kolupaeva, Mathematical Model of the Formation of a Crystallographic Shear Band in FCC Metals Taking Account for Elastic Interaction of Dislocations, Russian Physics Journal, 56(2013), no. 8, 953-958. 
[16] S.N.Kolupaeva, A.E.Petelin, Yu.P.Petelina, K.A.Polosukhin, Investigation of the Dynamics of a Screw Dislocation in Copper, Russian Physics Journal, 58(2015), no. 4, 461-464.

\section{Математическое моделирование пластической деформации в ГЦК-металлах}

Светлана Н. Колупаева

Томский государственный архитектурно-строительный университет Соляная, 2, Томск, 634003

Александр Е. Петелин Валерий И. Рюмкин

Национальный исследовательский Томский государственный университет Ленина, 36, Томск, 634050 Россия

$\overline{П р о в е д е н о ~ и с с л е д о в а н и е ~ и з м е н е н и я ~ к о л и ч е с т в а ~ д и с л о к а ц и и ̆ ~ в ~ з о н е ~ к р и с т а л л о г р а ф и ч е с к о г о ~ с д в и г а ~}$ для ГЦК-металлов: свинца, алюминия и меди, в зависимости от значения действующего напряжения и других факторов, влияющих на формирование зоны сдвига с использованием математической модели, в которой учтены основные механизмы сопротивления распространению дислокационной петли.

Ключевые слова: пластическая деформачия, дислокачия, кристаллографическое сколъжение, зона сдвига, ГЦК-материалы, математическое моделирование. 